\title{
The effect of intra-vaginal oxytocin on sexual function in breastfeeding mothers: a randomized triple-blind placebo-controlled trial
}

\author{
Arezu Mesbahi ${ }^{1}$, Sakineh Mohammad-Alizadeh-Charandabi ${ }^{2}$ Zahra Ghorbani ${ }^{3}$ and Mojgan Mirghafourvand ${ }^{4 *}$
}

\begin{abstract}
Background: Considering the importance of sexual function, high prevalence of sexual dysfunction (especially dyspareunia caused by atrophic vaginitis) in breastfeeding women, and lack of effective interventions, the present research aimed to determine the effect of oxytocin (OXT) vaginal gel on sexual function (primary outcome), sexual satisfaction, and depression (secondary outcomes) in the breastfeeding women.
\end{abstract}

Methods: This randomized triple-blind controlled trial was conducted on 64 breastfeeding women who referred to health centers in the city of Tabriz, Iran, in 2020-21. Participants were equally assigned to intervention/control groups using block randomization. $200 \mathrm{IU}$ of OXT vaginal gel was given to the participants in the intervention group daily for eight week and the same protocol was carried out for the control group with placebo. Standard questionnaires of Female Sexual Function Index (FSFI), Edinburgh Postpartum Depression Scale (EPDS) and Sexual satisfaction scale for women (SSSW) were completed at baseline and 8 weeks after intervention. ANCOVA test was used to compare postintervention mean score of the groups, adjusted for the baseline values.

Results: After intervention, there was no statistically significant difference between groups in terms of mean total score of FSFI (Adjusted Mean Difference (AMD): 1.14; 95\% Confidence Interval (95\% Cl): -1.28 to 9.16; P=0.349) and sexual satisfaction (AMD: $5.01 ; 95 \% \mathrm{Cl}$ : -0.53 to 10.56 ; $\mathrm{P}=0.075$ ). However, there was statistically significant difference between the groups in terms of mean scores of sexual contentment (AMD: 1.56; 95\% Cl: 0.29 to 2.83; P = 0.017) and depression (AMD: $-1.90 ; 95 \% \mathrm{Cl}$ : -1.27 to -2.54 ; $\mathrm{P}<0.001$ ). One participant in the OXT group and one participant in the placebo group reported mild uterine contraction and one person in the placebo group reported vaginal burning sensations.

Conclusions: No evidence was found for the effects of OXT gel in the improvement of FSFI, even though, OXT significantly improved sexual satisfaction in the domain of contentment, and improved the symptoms of depression in comparison to the placebo group. However, a definite conclusion requires more research in this regard.

Trial registration: the Iranian Registry of Clinical Trials (IRCT), code: IRCT20120718010324N55, Date of registration: 27/05/2020, URL: https://en.irct.ir/user/trial/44986/view.

Keywords: Intravaginal Oxytocin, Sexual function, Sexual dysfunction, Breastfeeding mothers, Postpartum

\footnotetext{
*Correspondence: mirghafourvand@gmail.com

${ }^{4}$ Social Determinants of Health Research Center, Faculty of Nursing

and Midwifery, Tabriz University of Medical Sciences, Tabriz, Iran

Full list of author information is available at the end of the article
} original author(s) and the source, provide a link to the Creative Commons licence, and indicate if changes were made. The images or other third party material in this article are included in the article's Creative Commons licence, unless indicated otherwise in a credit line to the material. If material is not included in the article's Creative Commons licence and your intended use is not permitted by statutory regulation or exceeds the permitted use, you will need to obtain permission directly from the copyright holder. To view a copy of this licence, visit http://creativecommons.org/licenses/by/4.0/. The Creative Commons Public Domain Dedication waiver (http://creativeco mmons.org/publicdomain/zero/1.0/) applies to the data made available in this article, unless otherwise stated in a credit line to the data. 


\section{Background}

Pregnancy and childbirth cause hormonal and physical changes in the person and exert considerable effects on the health of the mothers and the quality of their lives [1]. Sexual function undergoes changes during the disparate periods of a woman's life and one of these periods that is less considered is the postpartum period [2]. The changes during the postpartum period include pain during coitus, reduction or lack of sexual desire, and failure to achieve orgasm [3]. The studies indicated that $91 \%$ of women suffer from sexual problems during the postpartum period, especially loss of sexual desire, dyspareunia, and atrophic vaginitis $[4,5]$.

Sexual satisfaction is one of the physiological needs that leads to human health. Lack of sexual satisfaction, and physical and psychological pressures caused by it can result in disorders and reduce a person's capabilities as well as creativity [7]. Sexual dysfunction is a chain of sexual-psychological disorders [6]. The results of the review of the literature indicated that there is a bilateral relationship between female sexual dysfunction (FSD) and depression [8-10]. Both sexual dysfunction and depression are more prevalent in women, during the postpartum period $[11,12]$. The results of Natsal- 3 cohort study showed that depression is one of the most prevalent common diseases with FSD [13]. As a result, simultaneous screening in people with FSD and women who gave birth recently is considerably important [3].

A variety of methods were employed in order to prevent and treat FSD. Hormone replacement therapy (HRT) is one of the most common methods for improving the sexual function. However, these drugs (especially estradiol) cannot be used by breastfeeding mothers since they have a considerable impact on the quality and quantity of the breast milk. Treatment with topical lubricant gels is one of the methods used during breastfeeding with no enough effect [7]. One of the hormones recently studied by researchers to treat sexual disorder is the oxytocin (OXT) hormone. Besides fewer side effects, this method can lead to more benefits than the common systematic and topical treatments [14-18].

OXT is a nine-amino-acid peptide hormone produced in the supraoptic and paraventricular nucleus of the hypothalamus and released into blood flow through the posterior pituitary [18]. The most known performance of OXT is during the start and progression of the process of childbirth and facilitation of milk secretion after childbirth [16]. OXT has a crucial role in regulating the mood, forming social interactions, mother-child attachment, and creating a sense of trust and intimacy in the interpersonal and marital relationship. OXT operates centrally in the central nervous system and environmentally in various tissues such as the ovary, testis, gastrointestinal system, and cardiovascular system through OXT receptors [19-22].

Several studies argued that disruption in the hormones secreted from the hypothalamic-pituitary-adrenal (HPA) axis can cause sexual dysfunction. Some studies have shown positive effect of intranasal OXT on the intensity of orgasm, arousal, and sexual satisfaction in women and men with sexual dysfunction [23-26]. One of the key mechanisms of OXT is stimulating the growth of natural cells in the body, which operates as a growth factor similar to growth factors of nerves and insulin. Furthermore, in the laboratory and animal tests, OXT restored the ulcers and damages to environmental nerves and recovered the skin and epithelium of the vagina through anti-inflammatory processes and secreting inflammatory cytokines. OXT accelerates the scar healing process of various cells through mechanisms such as increasing the tissue perfusion, increasing the secretion of the disparate growth factors, and stimulation of mitosis. Effective factors on reducing or improving the symptoms of atrophic vaginitis might follow a similar path [18, 27].

Taking into account the already stated mechanism of action of this hormone, psychologists and sex therapists recently become interested in this subject. Therefore, prescribing exogenous OXT may reduce and improve sexual disorders, especially sexual dysfunction caused by atrophic vaginitis in breastfeeding women. The present research aimed to determine the effect of OXT vaginal gel on sexual function (primary outcome), sexual satisfaction, and depression (secondary outcomes) in the breastfeeding mothers.

\section{Methods}

\section{Study design and participants}

This is a randomized, placebo-controlled, triple-blind trial. The trial conducted on breastfeeding women covered by the health centers in the city of Tabriz, Iran, in 2020-21. The participants, outcome assessors, and data analysts were not aware of the interventions received by each participant.

Participants were married healthy breastfeeding women (with no records of childbirth complications or illness), with a constant and healthy sexual partner, were sexually active, and 6 weeks to 6 months had passed from their childbirth. Women who obtained a score of less than 28 in the Female Sexual Function Index (FSFI) and a score of less than 13 in the Edinburgh Postpartum Depression Scale (EPDS) were included in the study. Use of highly effective contraceptive method was another inclusion criterion. The exclusion criteria were being pregnant, having postpartum depression, consumption of antidepressants and other nervous system drugs, 
hormonal treatment due to female sexual dysfunction, pelvic radiotherapy and chemotherapy, or any uncontrolled and chronic disease such as diabetes.

\section{Sample size}

The sample size was calculated in accordance with the sexual function variable and using G-Power software. According to the study by Sehhatie et al., [28] regarding the sexual function and by considering $\mathrm{M}_{1}=16.4$ (preintervention mean) and $\mathrm{M}_{2}=19.68$ (assuming a 20\% increase due to intervention), $\mathrm{SD}_{1}=\mathrm{SD}_{2}=4.3, \alpha=0.05$, Power $=90 \%$, sample size was calculated to be equal to 31 participants in each group. The total final sample size amounted to 34 , taking into account $10 \%$ attrition.

\section{Sampling}

After approval of the Ethics Committee of Tabriz University of Medical Sciences (IR.TBZMED.REC.1396.715), and registration of the study in the Iranian Registry of Clinical Trials (IRCT20120718010324N32), the researcher attended the health centers in the city of Tabriz-Iran for sampling. There are 80 health centers in Tabriz city. Participants were selected from the ten crowded centers with different socio-economic classes. Information of all women, either pregnant or who gave birth, was available in the household health information system. The principal investigator (AM) extracted phone number of potentially eligible women from the system, contacted and explained them the objectives of the study, and invited them to attend the health center. Women who were willing to participate were included in the study after assessing the inclusion and exclusion criteria and obtaining the written informed consent. Then, the scales were completed by all participants. Furthermore, anthropometric indices were calculated including weight and height (to measure the body mass index (BMI)), waist circumference, and blood pressure.

\section{Randomization and intervention}

The participants were randomly assigned into two groups (recipient of OXT or placebo vaginal gel) via the www. random.org website and using block randomization with block sizes of 8 and 10. In order to conceal allocation, the drug/placebo was packaged in identical consecutively numbered packages. The allocation generation and preparation of the packages were carried out by a person not involved in the processes of data collection and analysis.

Raw materials of OXT were supplied from the Caspian Tamin Pharmaceutical Company. The gel and the placebo were prepared in the Faculty of Pharmacy of Tabriz University of Medical Science. Placebo was a water-based gel with neutral $\mathrm{pH}$ that was contained carbomer 934, Methyl and propyl paraben as a preservative (prevent from growth of microorganisms). OXT gel was exactly the same as placebo, except that it contains $200 \mathrm{IU}$ of the active ingredient OXT powder. Each IU of OXT is equivalent to $1.67 \mu \mathrm{g}$, so $200 \mathrm{IU}$ of OXT is equal to $344 \mu \mathrm{g}$. The placebo gel and tubes were exactly the same color, odor and size as OXT gel and tubes. In the present research, $200 \mathrm{IU}$ of OXT vaginal gel was given to the women in the intervention group once a day for eight weeks and the same protocol was carried out for the control group with placebo drug. Drug/placebo gel was used by the participants using applicators at any hour of the day and with the maximum of half an hour prior to sexual intercourse. Four OXT or placebos gel tubes were provided for each participant, and an OXT or placebo gel tube were delivered to the participants once every two weeks in the health centers. Therefore, the investigator followed-up the participants once every two weeks to remind and to emphasize regular consumption of the drugs.

\section{Tools}

The data were collected using the sociodemographic and obstetrics information questionnaire, FSFI, Sexual satisfaction scale for women (SSSW), EPDS, and a checklist of the side effects. The Persian version of the EPDS, FSFI and SSSW have been approved in Iran after obtaining permit from the copyright holders of the English version of the scales. The used scales are available as Appendix.

\section{FSFI}

FSFI is a standard and international self-report tool used for the assessment of the sexual function of women, which was first designed by Rosen [29]. This questionnaire contains 19 items that measure women's sexual function in six domains. Each domain includes the following weight coefficient and a number of items. Sexual desire ( 2 items ${ }^{*} 0.6$ ), arousal ( 4 items*0.4), lubrication (4 items*0.4), orgasm (3 items*0.3), satisfaction (3 items ${ }^{*} 0.3$ ), and pain ( 3 items $s^{*} 0.3$ ). The total score of FSFI was obtained from the sum of the scores at each domain and considering their specific coefficients. The total sexual function score ranged between 2 and 36 . FSFI $<28$ was considered as sexual dysfunction. In this index, the highest score shows the desirable sexual function. The validity and reliability of FSFI were confirmed by Fakhri et al. and Mohammadi et al. in Iran [30, 31].

\section{SSSW}

In the present research, the SSSW was used to measure women's sexual satisfaction, which included 30 questions in five domains: contentment (questions 1 to 6), communication (questions 7 to 12), compatibility (questions 13 to 18), relational concern (questions 19 to 24), and personal concern (questions 25 to 30). In this questionnaire, 
the 5 points Likert scale was used, i.e. absolutely agree 1 point, agree 2 points, I don't know 3 points, disagree 4 points, absolutely disagree 5 points. Inverted scoring was used for questions $1,4,5,6,9,10,11$, and 12 . The score of each domain were obtained using sum score of related questions; with the higher score, the more sexual satisfaction. The validity and reliability of this tool were confirmed by Roshan Chesli et al. [32].

\section{EPDS}

EPDS was employed for the assessment of depression. It was designed by Cox et al. [33] and is used to measure pregnancy and postpartum depression. This tool includes 10 questions with four options scored 0-3. In some questions, the order of the options was from less to high severe (items 1,2, and 4) and some were ordered from high to low (items 10, 9, 8, 7, 6, 5, and 3). The total score which is varied from zero to 30 , is obtained from summing up the question scores. Those with score of higher than 12 suffer from depression. The validity and reliability of this scale were approved by Montazeri et al. [34].

\section{Checklist of side effects}

In the present research, the side effects were extracted through searching from scientific data bases and literature review and were listed in a checklist which included nausea, vomiting, headache, uterine contractions, vaginal itching and burning sensations. Any reported side effects by participants were also recorded.

\section{Medication recording checklist}

To assess compliance with the medication, the participants were requested to record their intake of the gel in a medication recording checklist. The checklist was provided to participants in the first visit. Also for assessing adherence to treatments, telephone calls were made weekly to emphasis the regular use of the medications and assess the side effects and potential withdrawals.

\section{Data analysis}

The data were analyzed using SPSS software version 24 . Kolmogorov-Smirnov test was used to determine the normality of the quantitative data. All data had normal distribution. After the intervention, ANCOVA test adjusted for the baseline scores was used to compare the mean scores of sexual function, sexual satisfaction and depression between groups. Mann Whitney $U$ test was used to compare the change in depression score (EPDS at 8 weeks - EPDS at baseline) between the two groups as a sensitivity analysis to confirm the results. Subgroup analysis was done based on the delivery type by using ANCOVA test. The Mann Whitney U test and subgroup analyses were post-hoc, following reviewers' suggestions. The level of significance was considered less than 0.05 .

\section{Results}

\section{Baseline characteristics}

All 200 breastfeeding women selected from the health centers' electronic system underwent screening in terms of eligibility criteria in the first assessment. Among them, 44 women were excluded from the study due to medical problems and childbirth complications, consumption of drugs affecting sexual function, and problems pertinent to the child, and 46 people were not interested in participating in the study. 64 out of 100 participants who fulfilled the FSFI questionnaire were identified as having sexual dysfunction $(\mathrm{FSFI}<28)$ and included in the study. The rest of questionnaires were completed after obtaining informed written consent. The participants were randomly assigned into two groups, i.e. OXT vaginal gel group $(\mathrm{n}=34)$ and the placebo group $(\mathrm{n}=30)$. There was no loss to follow-up and all participants in both groups continued the intervention up to eight weeks. After completion of the study, all questionnaires were filled in by the participants (Fig. 1).

Table 1 shows the socio-demographic and obstetrics characteristics of the participants by their groups. There was no statistically significant difference between the two groups except of age $(P>0.05)$. The variable of age was adjusted in the ANCOVA models.

\section{Sexual function}

The mean (SD) total score of FSFI in the OXT group was 19.48 (4.68) before the intervention and 27.50 (5.12) after the intervention, and in the placebo group, it was 22.28 (4.15) before the intervention and 28.14 (4.77) after the intervention. Based on the ANCOVA test with adjusting the baseline value and age, there was no statistically significant difference between groups in terms of the total score of sexual function (AMD: 1.14; 95\% CI: -1.28 to 9.16; $\mathrm{P}=0.349$ ). Table 2 shows the mean total score of sexual function and all of its domains by the two groups, before and after the intervention.

\section{Sexual satisfaction}

The mean (SD) sexual satisfaction was 98.35 (17.64) before the intervention and 106.44 (21.7) after the intervention in the OXT group and in the placebo group, it was 109.37 (15.94) before the intervention and 113.23 (16.48) after the intervention. After the intervention, there was no statistically significant difference between the two groups after adjusting the baseline value and age (it was borderline evidence in terms of sexual satisfaction) (AMD: 5.01; 95\% CI: -0.53 to 10.56; $\mathrm{P}=0.075$ ). Among the five domains, only sexual contentment 


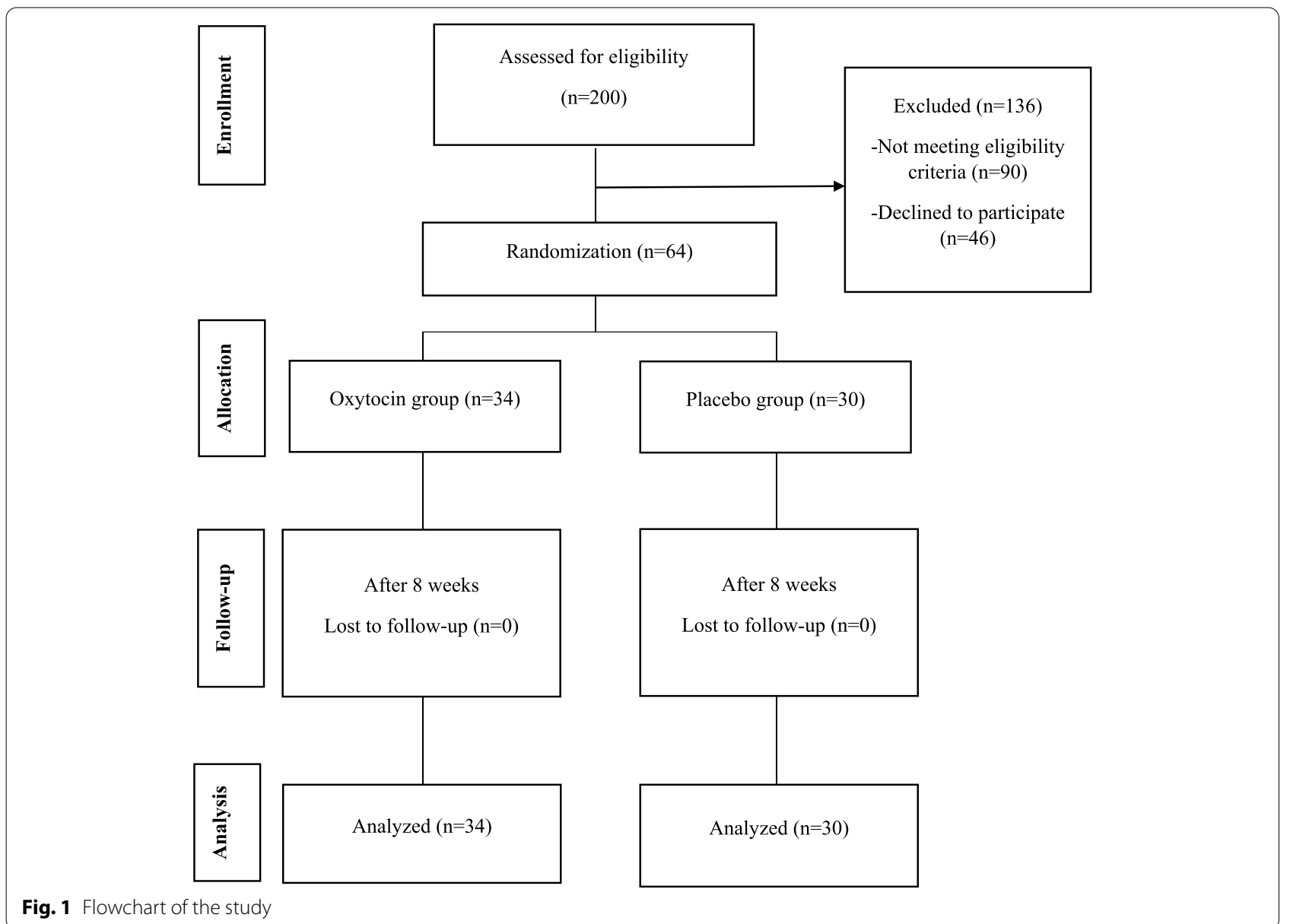

was significantly higher in the OXT group compared to the placebo group (AMD: 1.56; 95\% CI: 0.29 to 2.83; $\mathrm{P}=0.017$ ). Table 3 shows the total mean sexual satisfaction and all of its domains by the groups.

\section{Depression}

The mean (SD) depression score was 6.32 (3.8) before the intervention and 4.59 (2.40) after the intervention in the OXT group and in the placebo group, it was 7.03 (5.16) before the intervention and 6.63 (2.43) after the intervention. After the intervention, the mean depression score after adjusting the baseline value and age statistically lower in the OXT group than the placebo group (AMD: $-1.90 ; 95 \%$ CI: -1.27 to $-2.54 ; \mathrm{P}<0.001$ ) (Table 4). The results of Mann Whitney $U$ test showed statistically significant difference between the groups in terms of the change in depression score (EPDS at 8 weeks - EPDS at baseline $)(\mathrm{P}<0.001)$.

\section{Subgroup analysis based on the delivery type}

In both study groups, there was no statistically significant difference between the two subgroups of women with vaginal delivery and cesarean delivery in terms of mean total scores of FSFI, sexual satisfaction and depression. Also, the interaction between study groups and delivery types was not significant $(\mathrm{P}>0.05)$ (Table 5).

\section{Side Effects}

One participant in the OXT group and one participant in the placebo group reported mild uterine contraction and one person in the placebo group reported vaginal burning sensations. All participants in the two groups used their medication (OXT or placebo) regularly.

\section{Discussion}

This trial found no evidence of a significant effect of OXT on the primary outcome (sexual function), but indicated some benefits on wellbeing and possibly on sexual satisfaction".

In the present research, no evidence was found of an effect of OXT on the sexual function. We found 6 studies examining the effects of intranasal OXT on the sexual function of men and women. Even though in these studies the intranasal OXT resulted in the improvement 
Table 1 Socio-demographic and obstetrics characteristic of the participants in the study groups

\begin{tabular}{|c|c|c|}
\hline \multirow[t]{2}{*}{ Variables } & \multirow{2}{*}{$\begin{array}{l}\text { Oxytocin }(\mathrm{n}=34) \\
\text { Number (Percent) }\end{array}$} & \multirow{2}{*}{$\begin{array}{l}\text { Placebo }(\mathrm{n}=30) \\
\text { Number (Percent) }\end{array}$} \\
\hline & & \\
\hline Age (year) ${ }^{a}$ & $31.2(5.1)$ & $27.8(5.9)$ \\
\hline \multicolumn{3}{|l|}{ Level of education } \\
\hline Illiterate & $1(2.9)$ & $2(6.7)$ \\
\hline Elementary & $6(17.6)$ & $1(3.3)$ \\
\hline Secondary & $5(14.7)$ & $10(33.3)$ \\
\hline High school & $3(8.8)$ & $8(26.7)$ \\
\hline Diploma & $9(26.5)$ & $5(16.7)$ \\
\hline University & $10(29.4)$ & $4(13.3)$ \\
\hline \multicolumn{3}{|l|}{ Spouse's Education } \\
\hline \multicolumn{3}{|l|}{ Illiterate } \\
\hline Elementary & $6(1.6)$ & $6(20.0)$ \\
\hline Secondary & $7(20.6)$ & $7(23.3)$ \\
\hline High school & $5(14.7)$ & $2(6.7)$ \\
\hline Diploma & $6(17.6)$ & $10(33.3)$ \\
\hline University & $10(29.4)$ & $5(16.7)$ \\
\hline \multicolumn{3}{|l|}{ Job } \\
\hline Housekeeper & $27(79.4)$ & $28(93.3)$ \\
\hline Employed indoors & $1(2.9)$ & $1(3.3)$ \\
\hline Employed outdoors & $6(17.6)$ & $1(3.3)$ \\
\hline \multicolumn{3}{|l|}{ Spouse's Job } \\
\hline Unemployed & $0(0)$ & $1(3.3)$ \\
\hline Worker & $4(11.8)$ & $10(33.3)$ \\
\hline Retired & $1(2.9)$ & $0(0)$ \\
\hline Self employed & $20(58.8)$ & $15(50)$ \\
\hline Private sector employee & $2(5.9)$ & $0(0)$ \\
\hline Public sector employee & $7(20.6)$ & $4(13.3)$ \\
\hline \multicolumn{3}{|l|}{ Parity } \\
\hline 1 & $11(32.4)$ & $9(30.1)$ \\
\hline 2 & $12(35.3)$ & $18(60)$ \\
\hline 3 & $8(23.5)$ & $3(10)$ \\
\hline 4 & $2(5.9)$ & $0(0)$ \\
\hline 5 & $1(2.9)$ & $0(0)$ \\
\hline \multicolumn{3}{|l|}{ Delivery type } \\
\hline Vaginal with episiotomy & $10(29.4)$ & $14(46.7)$ \\
\hline Vaginal without episiotomy & $0(0)$ & $3(10.0)$ \\
\hline Elective cesarean section & $16(47.1)$ & $9(30.0)$ \\
\hline Emergency cesarean section & $8(23.5)$ & $4(13.3)$ \\
\hline \multicolumn{3}{|l|}{ Abortion } \\
\hline Yes & $10(29.4)$ & $13(43.3)$ \\
\hline No & $24(70.6)$ & $17(56.7)$ \\
\hline \multicolumn{3}{|l|}{ Family Members number } \\
\hline $1-3$ & $21(61.8)$ & $17(56.7)$ \\
\hline $4-6$ & $11(32.4)$ & $10(3.33)$ \\
\hline$>6$ & $2(5.9)$ & $3(10)$ \\
\hline \multicolumn{3}{|c|}{ Sufficiency of monthly income } \\
\hline Inadequate & $7(20.6)$ & $7(23.3)$ \\
\hline Relatively adequate & $25(73.5)$ & $21(70)$ \\
\hline More than adequate & $2(5.9)$ & $2(6.7)$ \\
\hline
\end{tabular}


Table 1 (continued)

\begin{tabular}{|c|c|c|}
\hline \multirow[t]{2}{*}{ Variables } & \multirow{2}{*}{$\begin{array}{l}\text { Oxytocin }(\mathrm{n}=34) \\
\text { Number (Percent) }\end{array}$} & \multirow{2}{*}{$\begin{array}{l}\text { Placebo }(n=30) \\
\text { Number (Percent) }\end{array}$} \\
\hline & & \\
\hline \multicolumn{3}{|l|}{ Life satisfaction } \\
\hline Satisfied & $28(482)$ & $29(96.7)$ \\
\hline No idea & $4(11.8)$ & $14(3.3)$ \\
\hline Dissatisfied & $2(5.9)$ & $0(0)$ \\
\hline \multicolumn{3}{|l|}{ Live with spouse's family } \\
\hline Yes & $6(17.6)$ & $11(36.7)$ \\
\hline No & $28(82.4)$ & $19(63.3)$ \\
\hline \multicolumn{3}{|l|}{ Spouse's smoking } \\
\hline Yes & $11(32.4)$ & $11(36.7)$ \\
\hline No & $23(67.67)$ & $19(63.3)$ \\
\hline \multicolumn{3}{|l|}{ Infant other nutrition } \\
\hline Yes & $20(58.8)$ & $11(36.7)$ \\
\hline No & $14(41.2)$ & $19(63.3)$ \\
\hline Infant age (Month) & $4.18(1.88)$ & $3.87(1.72)$ \\
\hline Waist circumference $(\mathrm{cm})$ & $77.18(13.06)$ & $75.50(11.69)$ \\
\hline Hip circumference ${ }^{a}(\mathrm{~cm})$ & $93.35(10.92)$ & $92.03(8.22)$ \\
\hline \multicolumn{3}{|l|}{ Blood pressure (mmHg) } \\
\hline Systole ${ }^{a}$ & $111.32(9.32)$ & $111.00(11.73)$ \\
\hline Diastole ${ }^{a}$ & $68.23(11.21)$ & $70.00(11.45)$ \\
\hline Body mass index ${ }^{\mathrm{a}}\left(\mathrm{kg} / \mathrm{m}^{2}\right)$ & $25.65(2.75)$ & $25.28(3.94)$ \\
\hline
\end{tabular}

a The numbers were reported as mean (standard deviation)

of disparate parameters of sexual function in men and women, these changes were not statistically significant in comparison to the placebo group. Merely in some studies, it had considerable effects on the intensity of orgasm and the increase of the heart rate caused by orgasm in men [23-26, 35-37]. In the present research, placebo manifested considerable effects, which can be due to the beneficial effects of the placebo gel. The results of the present research correspond to the results of the study by Mitchell et al. (2018). They assigned 302 healthy post-menopausal women who were sexually active and had mild to severe symptoms of atrophic vaginitis into three groups; receiving vaginal estradiol, over-the-counter lubricant gel, or placebo gel. Surprisingly, the three groups manifested no statistically significant differences [38]. In accordance with the meta-analysis results of a systematic review, a considerable placebo effect has been reported in most clinical trials on female sexual function disorder. This demonstrates that $67.7 \%$ of the therapeutic effects in FSD were related to the placebo [39]. Another study by Shaughnessy et al. [40], revealed that vaginal estrogen has no superiority over lubricant placebo gel.

The results of the present research demonstrated that there was no significant difference between the two groups in terms of mean total score of sexual satisfaction and its subdomain except contentment domain. Sexual satisfaction requires normal sexual function on the basis of the stages of correspondence to the sexual stimuli (sexual desire, arousal, orgasm, and resolution) [41].

Furthermore, the results of the present research demonstrated that OXT significantly leads to the improvement of depression. The results of a study showed that intrapartum synthetic oxytocin predicted a significantly lower risk of postpartum depression [42]. Since, there is a bilateral relationship between sexual function and depression [8-10], it was expected that the effect of OXT on depression to be mediated through its effect on sexual function. As in this study, no evidence was found for the effects of OXT gel in the improvement of sexual function, it may be a direct effect (hormonal) of OXT on wellbeing. Given the results of some review studies in postpartum mothers and people with major depressive disorder reveal that there is a negative relationship between the severity of depression and the level of plasma OXT [4345], it is suggested that OXT plasma levels to be analysed after its intravaginal administration.

During the postpartum, the level of estrogen drops due to the sudden discontinuation of placental estrogen and high levels of prolactin hormone (as a potential antagonist in the secretion of ovary estrogen) $[46,47]$. This induced systematic hypoestrogenism can cause urogenital atrophy [48]. Therefore, managing atrophic 
Table 2 The mean FSFI total score and its dimensions in study groups

\begin{tabular}{lllll}
\hline $\begin{array}{l}\text { Variable } \\
\text { (score }\end{array}$ & Oxytocin & Placebo & AMD $(95 \% \mathrm{Cl})^{\mathrm{b}}$ & P-value \\
range) & Mean (SD) & $\mathrm{n}=30$ & & \\
& & Mean (SD) & & \\
\end{tabular}

\section{Desire (1.2-6)}

Baseline $\quad 2.91(0.96) \quad 3.42(0.74)$

8 weeks $\quad 4.38(1.00) \quad 4.34(1.13) \quad 0.32(0.86$ to -0.23$) \quad 0.253$

Arousal (0-6)

\begin{tabular}{|c|c|c|c|c|}
\hline Baseline & $1.04(2.98)$ & $3.49(0.74)$ & & \\
\hline 8 weeks & $4.41(1.09)$ & $4.46(1.04)$ & 0.32 (0.81 to -0.18$)$ & 0.208 \\
\hline \multicolumn{5}{|c|}{ Lubrication (0-6) } \\
\hline Baseline & $3.34(0.85)$ & $3.60(0.8)$ & & \\
\hline 8 weeks & $4.53(0.87)$ & $4.65(0.81)$ & $0.06(0.47$ to -0.36$)$ & 0.791 \\
\hline \multicolumn{5}{|c|}{ Orgasm (0-6) } \\
\hline Baseline & $3.21(1.00)$ & $2.76(1.1)$ & & \\
\hline 8 weeks & $4.46(1.00)$ & $4.53(1.03)$ & 0.34 (0.77 to 0.08 ) & 0.114 \\
\hline \multicolumn{5}{|c|}{ Satisfaction (0.8-6) } \\
\hline Baseline & $3.47(1.26)$ & $4.39(1.15)$ & & \\
\hline 8 weeks & $4.85(1.16)$ & $5.04(0.90)$ & $0.29(0.8$ to -0.21$)$ & 0.252 \\
\hline \multicolumn{5}{|c|}{ Pain (0-6) } \\
\hline Baseline & $3.56(1.24)$ & $3.63(4.46)$ & & \\
\hline 8 weeks & $4.88(1.13)$ & $5.12(0.98)$ & 0.11 (0.41 to -0.64$)$ & 0.664 \\
\hline \multicolumn{5}{|c|}{ Total FSFI score (2-36) } \\
\hline Baseline & $19.48(4.67)$ & $22.28(4.15)$ & & \\
\hline 8 weeks & $27.50(5.12)$ & $28.14(4.77)$ & 1.14 (3.57 to -1.28$)$ & 0.349 \\
\hline
\end{tabular}

a Mean (standard deviation)

b Adjusted mean difference (95\% confidence interval)

ANCOVA test adjusted for baseline score was used to compare the mean scores at post-intervention

Higher sexual function scores indicate more favorable conditions

vaginitis is crucial in order to preserve sexual and vaginal health and to prevent FSD. However, management of atrophic vaginitis in breastfeeding women requires a bilateral view of both mother and the infant. In addition, there are several restrictions in the systematic prescription of disparate chemical and herbal drugs for breastfeeding mothers since there is not enough information regarding the amount of secretion of the drug in mother's milk and its effect on the milk [49-51]. Even though the standard treatment of atrophic vaginitis in breastfeeding mothers (like menopausal women) is systematic estrogen, it affects the volume of a mother's milk, thus, the best therapeutic option for reducing or improving atrophic vaginitis in breastfeeding women are the topical products (vaginal) not the systematic products $[48,52]$. Another important factor is that some medicinal vaginal creams (not just for lubricant effects) can weaken the latex in people who use barrier methods for preventing pregnancy. Therefore, the most common methods for the management of atrophic
Table 3 The mean sexual satisfaction total score and its dimensions in study groups

\begin{tabular}{|c|c|c|c|c|}
\hline \multirow{2}{*}{$\begin{array}{l}\text { Variable } \\
\text { (Score } \\
\text { range) }\end{array}$} & \multirow{2}{*}{$\begin{array}{l}\text { Oxytocin } \\
\mathrm{n}=34 \\
\text { Mean (SD) }\end{array}$} & \multirow{2}{*}{$\begin{array}{l}\text { Placebo } \\
\mathrm{n}=30 \\
\text { Mean (SD) }\end{array}$} & \multirow[t]{2}{*}{ AMD $) 95 \%(\mathrm{Cl})^{b}$} & \multirow[t]{2}{*}{ P-value } \\
\hline & & & & \\
\hline \multicolumn{5}{|c|}{ Contentment (6-30) } \\
\hline Baseline & $19.21(4.33)$ & $22.7(4.6)$ & & \\
\hline 8 weeks & $21.56(3.98)$ & $23.17(4.62)$ & 1.56 (2.83 to 0.29$)$ & 0.017 \\
\hline \multicolumn{5}{|c|}{ Communication (6-30) } \\
\hline Baseline & $20.50(3.49)$ & $22.7(3.39)$ & & \\
\hline 8 weeks & $21.23(4.42)$ & $23.40(3.52)$ & 0.23 (1.49 to -1.03$)$ & 0.716 \\
\hline \multicolumn{5}{|c|}{ Coping (6-30) } \\
\hline Baseline & $18.85(5.21)$ & $22.13(4.31)$ & & \\
\hline 8 weeks & $19.68(5.45)$ & $22.27(4.42)$ & $0.12(1.45$ to -1.21$)$ & 0.856 \\
\hline \multicolumn{5}{|c|}{ Relation concern (6-30) } \\
\hline Baseline & $20.26(4.39)$ & $21.53(5.17)$ & & \\
\hline 8 weeks & $22.71(8.65)$ & $22.27(4.93)$ & 1.64 (4.67 to -1.32$)$ & 0.271 \\
\hline \multicolumn{5}{|c|}{ Personal concern (6-30) } \\
\hline Baseline & $19.53(5.42)$ & $20.23(5.84)$ & & \\
\hline 8 weeks & $21.26(5.59)$ & $21.70(5.11)$ & $0.47(1.822$ to 0.9$)$ & 0.498 \\
\hline \multicolumn{5}{|c|}{ Total Sexual Satisfaction (30-150) } \\
\hline Baseline & $98.35(17.64)$ & $109.37(15.94)$ & & \\
\hline 8 weeks & $106.44(21.7)$ & $113.2(16.48)$ & 5.01 (10.56 to -0.53$)$ & 0.075 \\
\hline \multicolumn{5}{|c|}{ a Mean (Standard Deviation) } \\
\hline \multicolumn{5}{|c|}{ b Adjusted mean difference ( $95 \%$ confidence interval) } \\
\hline \multicolumn{5}{|c|}{$\begin{array}{l}\text { ANCOVA test adjusted for baseline score was used to compare the mean scores } \\
\text { at post-intervention }\end{array}$} \\
\hline
\end{tabular}

Table 4 The mean depression score in study groups

\begin{tabular}{lllll}
\hline $\begin{array}{l}\text { Variable } \\
\text { (Score }\end{array}$ & Oxytocin & Placebo & AMD $(95 \% \mathrm{Cl})^{\mathrm{b}}$ & P-value \\
range) & Mean (SD) $)^{\mathrm{a}}$ & $\mathrm{n}=30$ & & \\
& Mean (SD) & & \\
& & &
\end{tabular}

\section{Depression (0-30)}

Baseline $\quad 6.32(3.8) \quad 7.03(5.16)$

8 weeks $\quad 4.59(2.40) \quad 6.63(2.43) \quad-1.90(-1.27$ to -2.54$) \quad<0.001$

a Mean (standard deviation)

${ }^{\text {b }}$ Adjusted mean difference (95\% confidence interval)

ANCOVA test adjusted for baseline score was used to compare the mean scores at post-intervention

The higher scores indicate the more severe condition

vaginitis in breastfeeding women are water-based lubricant vaginal gels $[49,53,54]$.

\section{Limitations, strengths and implications for practice}

The present research is the first study to examine the effects of OXT vaginal gel on sexual function in breastfeeding mothers while other studies focused on 
Table 5 Subgroup analysis of outcomes based on the delivery type

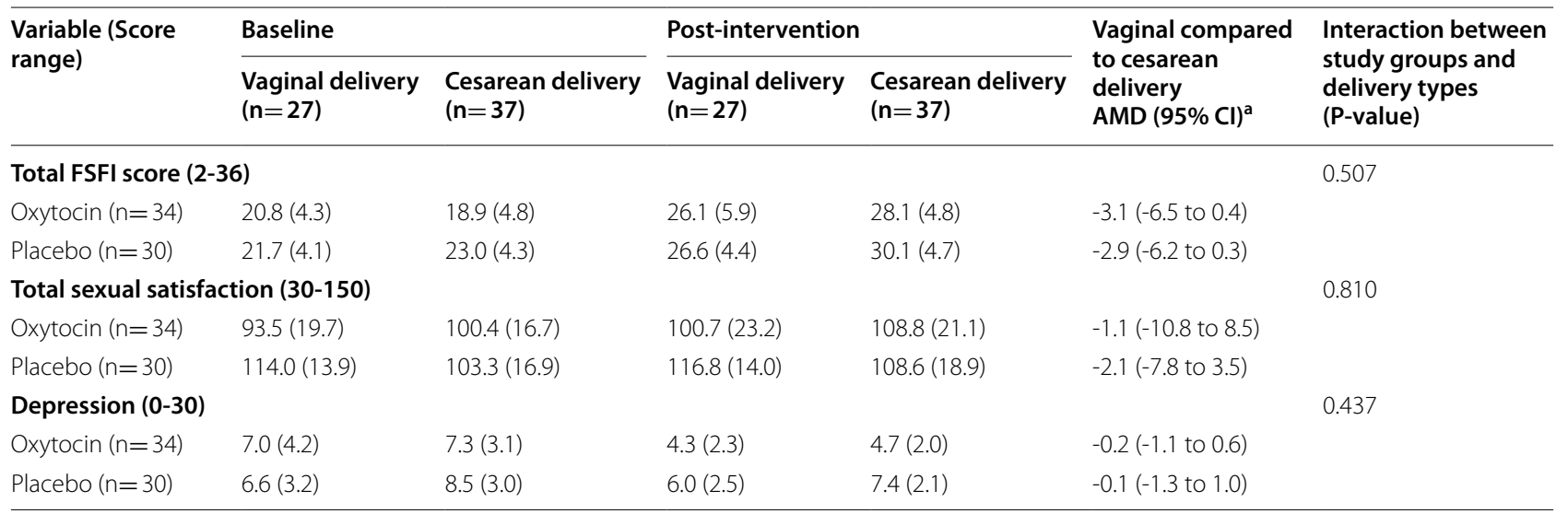

The data present mean (standard deviation) unless otherwise indicated

${ }^{a}$ Adjusted mean difference (95\% Confidence Interval)

ANCOVA test with adjusting for baseline score was used to compare the mean scores of outcomes between two types of delivery

For FSFI and sexual satisfaction, the higher score indicate the better condition and for depression, the higher scores indicate the more severe condition

menopausal women. The strengths of this study include randomization, triple blinding, and no attrition resulting in low risk of bias. In the present research, standard and valid questionnaires were used for assessment of the outcomes due to the financial limitations. However, examining the laboratory criteria such as vaginal maturation could be helpful in determining the effectiveness of OXT and the subjective criteria (questionnaires) alone may not be sufficient for assessment of effectiveness of a drug. Small sample size was another limitation of this study. It is difficult to know whether the "non-significant results" are due to a lack of treatment effect, or a lack of power.

In future clinical trials, assessment of OXT effect in other women with atrophic vaginitis and sexual dysfunction such as women suffering from premature ovarian failure (POF) or women suffering from atrophic vaginitis due to abdominal or pelvic radiotherapy or chemotherapy could be considered. As no definitive conclusion can be drawn from this trial, further trials of OXT in breastfeeding women are recommended.

\section{Conclusions}

No evidence was found for the effects of OXT gel in the improvement of sexual function, even though, OXT significantly improved sexual satisfaction in the domain of contentment, and improved the symptoms of depression in comparison to the placebo group. However, a definite conclusion requires more research in this regard.

\section{Abbreviations}

OXT: Oxytocin; FSFI: Female Sexual Function Index; EPDS: Edinburgh Postpartum Depression Scale; SSSW: Sexual Satisfaction Scale for Women; AMD: Adjusted mean difference; FSD: Female sexual dysfunction; HRT: Hormone replacement therapy; HPA: hypothalamic-pituitary-adrenal; IRCT: Iranian Registry of Clinical Trials; BMI: Body mass index; POF: Premature ovarian failure.

\section{Supplementary Information}

The online version contains supplementary material available at https://doi. org/10.1186/s12884-022-04384-w.

\section{Additional file 1.}

\section{Acknowledgements}

This study was extracted from the master's thesis in obstetrics. Hereby, we appreciate all participating in this study, especially the Caspian Tamin Pharmaceutical Company for providing raw materials of OXT as well as all participants of this study.

\section{Authors' contributions}

$\mathrm{AM}$ and ZG involved in the conception and design, acquisition of data and drafting the manuscript. MM involved in the conception and design, acquisition of data, blinded analysis of the data, interpretation of data and writing this manuscript. SMAC involved in the conception and design, interpretation of the data and revising this manuscript. All authors gave their final approval of this version to be published.

\section{Funding}

This research is supported by Tabriz University of Medical Sciences. The funding source had no involvement in design of the study, data collection, data analysis, etc.

\section{Availability of data and materials}

The datasets used and/or analyzed during the current study available from the corresponding author on reasonable request.

\section{Declarations}

Ethics approval and consent to participate

This research has been approved by the Ethics Committee of the Tabriz University of Medical Sciences, Tabriz, Iran (code number: IR.TBZMED.

REC.1396.715). All subjects were ensured about the matter of confidentiality and signed the informed written consent form. All methods were performed in accordance with the Declaration of Helsinki. 


\section{Consent for publication \\ Not applicable.}

\section{Competing interests}

The authors declare that they have no competing interests.

\section{Author details}

'Department of midwifery, Student Research Committee, Faculty of Nursing and Midwifery, Tabriz University of medical sciences, Tabriz, Iran. ${ }^{2}$ Midwifery Department, Faculty of Nursing and Midwifery, Tabriz University of Medical Sciences, Tabriz, Iran. ${ }^{3}$ Faculty of Nursing and Midwifery, Tehran University of Medical Sciences, Tabriz, Iran. ${ }^{4}$ Social Determinants of Health Research Center, Faculty of Nursing and Midwifery, Tabriz University of Medical Sciences, Tabriz, Iran.

Received: 31 May 2021 Accepted: 6 January 2022

Published online: 22 January 2022

\section{References}

1. Eid MA, Sayed A, Abdel-Rehim R, Mostafa T. Impact of the mode of delivery on female sexual function after childbirth. Int J Impot Res. 2015:27(3):118-20.

2. van Brummen HJ, Bruinse HW, van de Pol G, Heintz AP, van der Vaart $\mathrm{CH}$. Which factors determine the sexual function 1 year after childbirth? BJOG. 2006;113(8):914-8.

3. Olsson A, Lundqvist M, Faxelid E, Nissen E. Women's thoughts about sexual life after childbirth: focus group discussions with women after childbirth. Scand J Caring Sci. 2005;19(4):381-7.

4. Ustunsoz A, Guvenc G, Akyuz A, Oflaz F. Comparison of maternal-and paternal-fetal attachment in Turkish couples. Midwifery. 2010;26(2):e1-e9.

5. Mohammed YF, Hassan HM, AI-Dinary AM, Rashed NS. Sexual function after child birth according to the mode of delivery. AAMJ. 2014;12(4):264-84.

6. Cunningham S, Smith A, Kershaw T, Lewis J, Cassells A, Tobin J, et al. Prenatal depressive symptoms and postpartum sexual risk among young urban women of colorJ Pediatr Adolesc Gynecol. 2016;29(1):11-7.

7. Taylor HS, Pal L, Seli E. Speroff's clinical gynecologic endocrinology and infertility. Ninth edition. Philadephia: Wolters Kluwer; 2020.

8. Clayton $\mathrm{AH}$, Juarez EMV. Female sexual dysfunction. Med Clin. 2019:103(4):681-98.

9. Calabrò RS. Sexual dysfunction in patients with epilepsy: disentangling the pathogenic mechanisms! Epilepsy Behav. 2016;64:294.

10. Atlantis E, Sullivan T. Bidirectional association between depression and sexual dysfunction: a systematic review and meta-analysis. J Sex Med. 2012;9(6):1497-507.

11. McCabe MP, Sharlip ID, Lewis R, Atalla E, Balon R, Fisher AD, et al. Incidence and prevalence of sexual dysfunction in women and men: a consensus statement from the Fourth International Consultation on Sexual Medicine 2015. J Sex Med. 2016;13(2):144-52.

12. Rothmore J. Antidepressant-induced sexual dysfunction. Med J Aust. 2020;212(7):329-34

13. Polland AR, Davis M, Zeymo A, Iglesia CB. Association between comorbidities and female sexual dysfunction: findings from the third National Survey of Sexual Attitudes and Lifestyles (Natsal-3). Int Urogynecol J. 2019:30(3):377-83.

14. Al-Saqi SH, Jonasson AF, Naessen T, Uvnas-Moberg K. Oxytocin improves cytological and histological profiles of vaginal atrophy in postmenopausal women. Post Reprod Health. 2016;22(1):25-33.

15. Al-Sagi SH, Uvnas-Moberg K, Jonasson AF. Intravaginally applied oxytocin improves post-menopausal vaginal atrophy. Post Reprod Health. 2015;21(3):88-97.

16. Ludwig M, Leng G. Dendritic peptide release and peptide-dependent behaviours. Nat Rev Neurosci. 2006;7(2):126-36.

17. Torky HA, Taha A, Marie H, El-Desouky E, Raslan O, Moussa AA, et al. Role of topical oxytocin in improving vaginal atrophy in postmenopausal women: a randomized, controlled trial. Climacteric. 2018;21(2):174-8.

18. Uvnäs-Moberg K. Oxytocin may mediate the benefits of positive social interaction and emotions. Psychoneuroendocrinology. 1998;23(8):819-35.
19. Gutkowska J, Jankowski M, Antunes-Rodrigues J. The role of oxytocin in cardiovascular regulation. Braz J Med Biol Res. 2014;47(3):206-14.

20. Ohlsson B, Ringström G, Abrahamsson H, Simrén M, Björnsson E. Oxytocin stimulates colonic motor activity in healthy women. Neurogastroenterol Motil. 2004;16(2):233-40.

21. Petersson M, Lundeberg T, Sohlström A, Wiberg U, Uvnäs-Moberg K. Oxytocin increases the survival of musculocutaneous flaps. Naunyn Schmiedebergs Arch Pharmacol. 1998;357(6):701-4.

22. Viero C, Shibuya I, Kitamura N, Verkhratsky A, Fujihara H, Katoh A, et al. Oxytocin: crossing the bridge between basic science and pharmacotherapy. CNS Neurosci Ther. 2010;16(5):e138-e56.

23. Behnia B, Heinrichs M, Bergmann W, Jung S, Germann J, Schedlowski M, et al. Differential effects of intranasal oxytocin on sexual experiences and partner interactions in couples. Horm Behav. 2014;65(3):308-18.

24. Gossen A, Hahn A, Westphal L, Prinz S, Schultz R, Gründer G, et al. Oxytocin plasma concentrations after single intranasal oxytocin administration-a study in healthy men. Neuropeptides. 2012;46(5):211-5.

25. Muin DA, Wolzt M, Marculescu R, Sheikh Rezaei S, Salama M, Fuchs C, et al. Effect of long-term intranasal oxytocin on sexual dysfunction in premenopausal and postmenopausal women: a randomized trial. Fertil Steril. 2015;104(3):715-23.e4

26. Zhang Y, Deiter F, Jung S, Heinrichs M, Schedlowski M, Krüger H. Differential effects of intranasal oxytocin administration on sexual functions in healthy females: A laboratory setting. Eur Psychiatry. 2015;30(S1):1-.

27. Kallak TK, Uvnas-Moberg K. Oxytocin stimulates cell proliferation in vaginal cell line Vk2E6E7. Post Reprod Health. 2017;23(1):6-12.

28. Sehhatie F, Malakouti J, Mirghafourvand M, Khalilpoor S. Sexual Function and its Relationship to General Health in Postpartum Women. J Womens Health, Issues Care. 2016;5:2. https://doi.org/10.4172/23259795.1000221

29. Rosen CB, J. Heiman, S. Leiblum, C. Meston, R. Shabsigh, D. Ferguson, R. D'Agostino, R. The Female Sexual Function Index (FSFI): a multidimensional self-report instrument for the assessment of female sexual function. J Sex Marital Ther. 2000;26(2):191-208.

30. Fakhri A, Pakpour AH, Burri A, Morshedi H, Zeidi IM. The Female Sexual Function Index: translation and validation of an Iranian version. J Sex Med. 2012;9(2):514-23.

31. Mohammadi K, Heydari M, Faghihzadeh S. The female sexual function index (FSFI): validation of the Iranian version. Payesh. 2008;7(3):269-78.

32. Roshan Chesli R, Mirzaei S, Nikazin A. Validity and reliability of multidimensional sexual satisfaction scale for women (SSSW) in one sample of Iranian women. Clin Psychol Personal. 2014;12(1):129-40.

33. Cox JL, Holden JM, Sagovsky R. Detection of postnatal depression: development of the 10-item Edinburgh Postnatal Depression Scale. Br J Psychiatry. 1987;150(6):782-6.

34. Montazeri A, Torkan B, Omidvari S. The Edinburgh Postnatal Depression Scale (EPDS): translation and validation study of the Iranian version. BMC psychiatry. 2007;7(1):1-6.

35. Burri A, Heinrichs $M$, Schedlowski M, Kruger TH. The acute effects of intranasal oxytocin administration on endocrine and sexual function in males. Psychoneuroendocrinology. 2008;33(5):591-600.

36. Gregory R, Cheng H, Rupp HA, Sengelaub DR, Heiman JR. Oxytocin increases VTA activation to infant and sexual stimuli in nulliparous and postpartum women. Horm Behav. 2015;69:82-8.

37. Kruger THC, Deiter F, Zhang Y, Jung S, Schippert C, Kahl KG, et al. Effects of Intranasal Oxytocin Administration on Sexual Functions in Healthy Women: A Laboratory Paradigm. J Clin Psychopharmacol. 2018;38(3):239-42.

38. Mitchell CM, Reed SD, Diem S, Larson JC, Newton KM, Ensrud KE, et al. Efficacy of Vaginal Estradiol or Vaginal Moisturizer vs Placebo for Treating Postmenopausal Vulvovaginal Symptoms: A Randomized Clinical Trial. JAMA Intern Med. 2018;178(5):681-90.

39. Weinberger JM, Houman J, Caron AT, Patel DN, Baskin AS, Ackerman AL, et al. Female Sexual Dysfunction and the Placebo Effect: A Meta-analysis. Obstet Gynecol. 2018;132(2).

40. Shaughnessy AF. Estrogen No Better Than Vaginal Lubricant for Postmenopausal Vaginal Symptoms. Am Fam Physician. 2018;98(10).

41. Aghababaei S, Refaei M, Roshanaei G, Rouhani Mahmoodabadi SM, Heshmatian T. The Effect of Sexual Health Counseling Based on REDI Model on Sexual Function of Lactating Women with Decreased Sexual Desire. Breastfeed Med. 2020;15(11):731-8. 
42. Takács, L., Seidlerová, J.M., Štěrbová, Z. et al. The effects of intrapartum synthetic oxytocin on maternal postpartum mood: findings from a prospective observational study. Arch Womens Ment Health. 2019;22:48591. https://doi.org/10.1007/s00737-018-0913-3

43. Mah BL. Oxytocin, postnatal depression, and parenting: a systematic review. Harv Rev Psychiatry. 2016;24(1):1-13.

44. Massey SH, Backes KA, Schuette SA. Plasma oxytocin concentration and depressive symptoms: a review of current evidence and directions for future research. Depress Anxiety. 2016;33(4):316-22.

45. Moura D, Canavarro MC, Figueiredo-Braga M. Oxytocin and depression in the perinatal period - a systematic review. Arch Womens Ment Health. 2016;19(4):561-70.

46. Alder E, Cook A, Davidson D, West C, Bancroft J. Hormones, mood and sexuality in lactating women. Br J Psychiatry. 1986;148(1):74-9.

47. Convery KM, Spatz DL. Sexuality \& breastfeeding: what do you know? MCN Am J Matern Child Nurs. 2009;34(4):218-23.

48. Palmer AR, Likis FE. Lactational atrophic vaginitis. J Midwifery Womens Health 2003:48(4):282-4.

49. Anbaran ZK, Baghdari N, Pourshirazi M, Karimi FZ, Rezvanifard M, Mazlom SR. Postpartum sexual function in women and infant feeding methods. High Edu. 2015;62:16.9.

50. McBride HL, Kwee JL. Sex after baby: women's sexual function in the postpartum period. Curr Sex Health Rep. 2017;9(3):142-9.

51. Nordeng H, Havnen GC, Spigset O. Drug use and breastfeeding. Tidsskr Nor Laegeforen. 2012.

52. Wisniewski PM, Wilkinson EJ. Postpartum vaginal atrophy. Am J Obstet Gynecol. 1991;165(4):1249-54.

53. Fuentealba-Torres M, Cartagena-Ramos D, Lara LA, Alves JD, Ramos AC, Campoy LT, et al. Determinants of female sexual function in breastfeeding women. J Sex Marital Ther. 2019;45(6):538-49.

54. Gutzeit O, Levy G, Lowenstein L. Postpartum female sexual function: risk factors for postpartum sexual dysfunction. Sex Med. 2020;8(1):8-13.

\section{Publisher's Note}

Springer Nature remains neutral with regard to jurisdictional claims in published maps and institutional affiliations.

Ready to submit your research? Choose BMC and benefit from:

- fast, convenient online submission

- thorough peer review by experienced researchers in your field

- rapid publication on acceptance

- support for research data, including large and complex data types

- gold Open Access which fosters wider collaboration and increased citations

- maximum visibility for your research: over $100 \mathrm{M}$ website views per year

At BMC, research is always in progress.

Learn more biomedcentral.com/submissions 